\title{
The Assembly of C60 in Semicrystalline PLLA Matrix
}

\author{
Li Chen ${ }^{1 *}$, Xiujiang Pang ${ }^{2}$
}

(Received 12 October 2011; accepted 01 March 2012; published online 19 March 2012).

\begin{abstract}
It has increasingly become a research focus to build higher structure composed of C60. However, there has been very few reports on the influence of polymer addition on the self-assembling behavior of fullerene in organic solvents. In this research, big needle-like C60 assemblings have been obtained in the form of PLLA/C60 composites. The largest C60 needles can be observed by naked eyes. The amount of C60 in the composite influences the length of C60 needles to some extent. DSC results indicate C60 accelerates the crystallization and lift the relative crystallinity of PLLA matrix. the results also imply the addition of semicrystalline PLLA influence the assembling behavior of C60. i.e., the crystallization of PLLA accelerated by $\mathrm{C} 60$ also act a driving force for the enriching and the linear assembling of C60 in PLLA matrix via Van der Waals force.
\end{abstract}

Keywords: C60; Poly (L-lactide acid) (PLLA); Assembling

Citation: Li Chen and Xiujiang Pang, "The Assembly of C60 in Semicrystalline PLLA Matrix", Nano-Micro Lett. 4 (1), 30-33 (2012). http://dx.doi.org/10.3786/nml.v4i1.p30-33

\section{Introduction}

It has become one research focus to build higher structure composed of C60 fullerene. Novel lowdimensional materials of fullerenes have been extensively investigated up to now. For example, Nakanishi et al. have successfully prepared spherical vesicles, fibers, discs, cones by the self-assembly of fullerene derivatives in mixed solvents [1]. In addition, fullerene nanowiskers, nanowires or nanorods [2-4] have also been fabricated.

The development of aggregates with different morphologies and its aggregation mechanism in solution using well-defined polymeric system are of potential interest to the research community. The self-assembly of polymer-branched $\mathrm{C} 60$ have been reported in organic or aqueous solvents [5-8]. However, there are few reports describing the influence of polymer addition on the self-assembling behavior of fullerene in organic sol- vents $[9,10]$.

Biomass-derived poly (L-lactide acid)(PLLA) has been intensively explored because it is biodegradable, compostable, producible from renewable resources, while at the same time nontoxic to human body and environment. The enhancement of crystallinity with the aid of a nucleating agent is commercially advantageous to improve the mechanical properties and thermal stability of PLLA. It has been found that C60 is effective for accelerating both the cold and melt crystallization of PLLA, and the nucleating effect of C60 is even higher than that of montmorillonite and polysaccharides [11].

In this paper, C60 and PLLA were mixed by solution method, needle-shaped C60 assemblings were found in resultant PLLA composites. The morphology and chemical composition of the C60 needles were studied by optical microscope, scanning electron microscope (SEM) and energy dispersive spectra (EDS). The influence of $\mathrm{C} 60$ on the crystallization behavior of PLLA was also investigated through DSC technique. The lin-

\footnotetext{
${ }^{1}$ Key Lab of Rubber-plastics of Ministry of Education/Shandong Provincial Key Laboratory of Rubber-plastics, Qingdao University of Science \& Technology (QUST), Qingdao 266042, China

${ }^{2}$ College of Chemistry and Molecular Engineering, QUST, Qingdao 266042, China

*Corresponding author. E-mail: chl5590@163.com
} 
ear assembling mechanism of C60 in PLLA during the solvent evaporation was proposed.

\section{Experimental}

\section{Materials}

Natureworks PLLA 2002D (number-average molecular weight $(\mathrm{Mn})=1.8 \times 10^{5}$, weight-average molecular weight $\left.(\mathrm{Mw})=3.2 \times 10^{5}, \mathrm{Mw} / \mathrm{Mn}=1.78\right)$ was supplied by Cargill Dow LLC, USA. C60 was kindly supplied by NIMS (national institute for materials science) in Japan.

\section{Preparation of PLLA/C60 composites}

The PLLA/C60 composites were prepared by the solution mixing method using dichloromethane $\left(\mathrm{H}_{2} \mathrm{CCl}_{2}\right)$ as a solvent at $25^{\circ} \mathrm{C}$. The solutions were prepared by dissolving PLLA and C60 in some $\mathrm{H}_{2} \mathrm{CCl}_{2}$, respectively. Then, the PLLA solution and C60 solution were mixed in a tube and homogenized by ultrasonication for $2 \mathrm{~min}$. After that, the mixed solution was kept still and let the solvent evaporate very slowly until the composite film was dry. The obtained films were then further dried at room temperature in vacuum oven for $8 \mathrm{hrs}$. PLLA composites containing 0.5 wt $\%, 1$ wt $\%$ and $2 \mathrm{wt} \%$ of C60 were prepared.

\section{Characterizations}

The resultant PLLA/C60 composites were put on the sample platform and observed by using a stereoscopic zoom microscopic Nikon SMZ 1500(Nikon corporation, Japan). In order to study the morphology and composition of the $\mathrm{C} 60$ needle, the PLLA in composites were etched by some $\mathrm{H}_{2} \mathrm{CCl}_{2}$, one typical $\mathrm{C} 60$ needle without PLLA matrix was fixed onto copper grid followed by gilding, the microstructure and chemical composition of the C60 fiber were then studied by JSM7500F and its INCA EDS accessory. Thermal analysis was carried out on a DSC from TA Instruments (model DSC 2920). About $5 \mathrm{mg}$ samples was weighed and sealed in an aluminum pan. The samples were heated to $200^{\circ} \mathrm{C}$ at $10^{\circ} \mathrm{C} / \mathrm{min}$ and maintained for $5 \mathrm{~min}$, then quenched to $0^{\circ} \mathrm{C}$ at $-50^{\circ} \mathrm{C} / \mathrm{min}$ and maintained for $5 \mathrm{~min}$, and then reheated to $200^{\circ} \mathrm{C}$ at $10^{\circ} \mathrm{C} / \mathrm{min}$ and maintained for $5 \mathrm{~min}$ and the second heating curves are recorded. The melting enthalpy change was recorded to study the effect of C60 on the crystallinities of PLLA during the evaporation of solvent. The standard melting enthalpy value of fully crystallized PLLA is $93.6 \mathrm{~J} / \mathrm{g}$, the relative crystallinity $(\mathrm{Xc})$ of PLLA could be calculated in the following equation:

$$
\mathrm{X}_{\mathrm{C}}=\left(\Delta \mathrm{H}_{\mathrm{m}} / 93.6\right) \times 100 \%
$$

$\Delta \mathrm{H}_{\mathrm{m}}$ referred to the melting enthalpy change.

\section{Results and discussions}

\section{Morphology of C60 assemblings in PLLA matrix}

Stereoscopic microscope image in Fig. 1 showed the assembled C60s in PLLA matrix were like black straight needles. The amount of C60 in PLLA matrix have some influences on the length of assembled C60 needles, e.g., the black needles in PLLA composites with 1wt\% C60 was longer than those in PLLA composites containing $0.5 \mathrm{wt} \%$ or $2 \mathrm{wt} \% \mathrm{C} 60$, and the $\mathrm{C} 60$ needles in PLLA composites containing 2wt\% C60 were longer than those in PLLA composites containing $0.5 \mathrm{wt} \%$ C60. The length distribution of black C60 needles in Fig. (a), Fig. (b) and Fig. (c) was $60-110 \mu \mathrm{m}, 300-500 \mu \mathrm{m}$, and 200-300 $\mu \mathrm{m}$, respectively. The longest C60 needle in PLLA composites could reach over $1 \mathrm{~cm}$ long and could be easily seen by naked eyes. One typical C60 needle
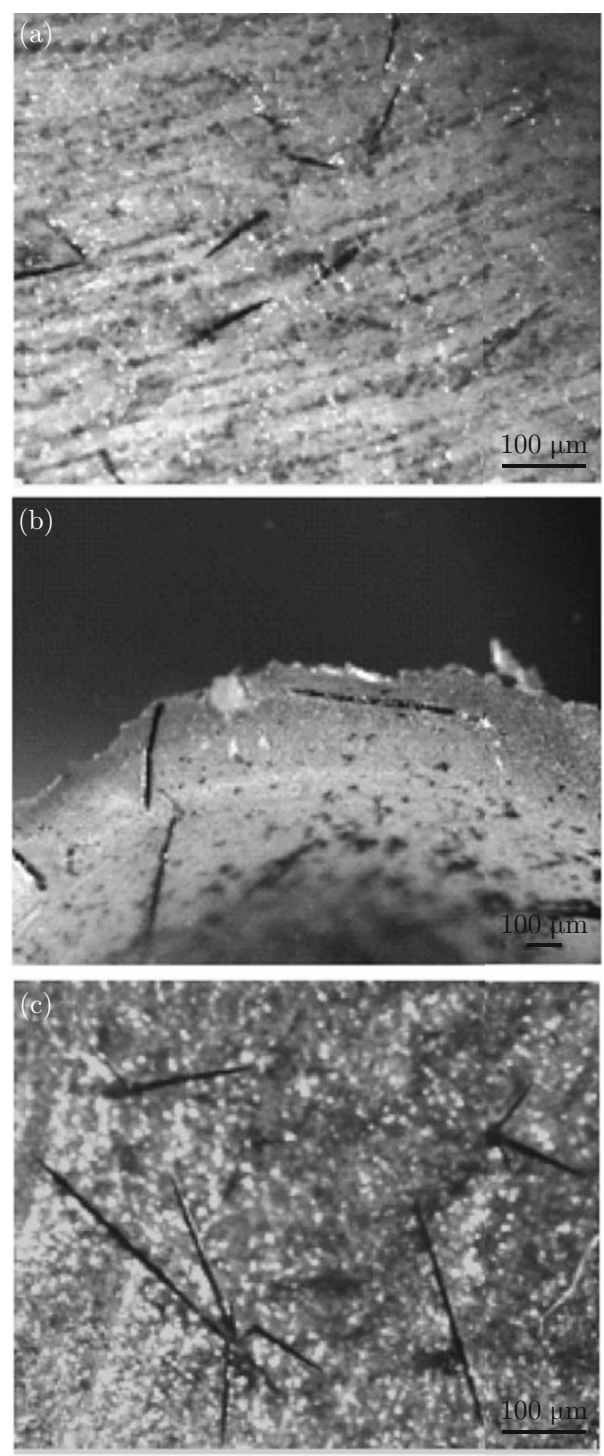

Fig. 1 Stereoscopic microscope images of PLLA films with (a) $0.5 \mathrm{wt} \%$, (b) $1.0 \% \mathrm{wt} \%$ and (c) $2.0 \mathrm{wt} \%$ C60, respectively. 
separated from the PLLA filled with 1wt\% C60 was further studied by SEM and showed a diameter of about $50 \mu \mathrm{m}$ and a length of $1.6 \mathrm{~mm}$ in the SEM image (Fig. 2).

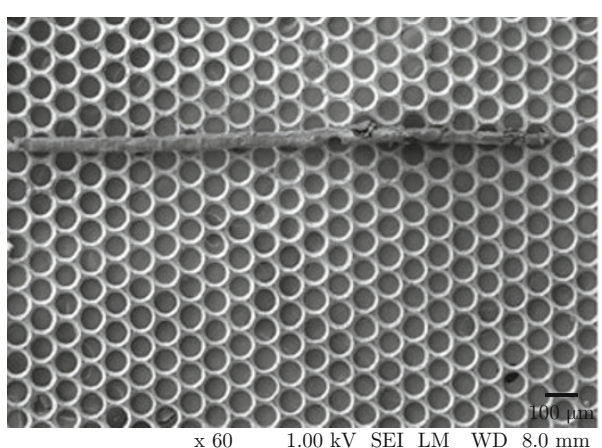

Fig. 2 SEM image of one C60 needle in PLLA composites containing $1 \mathrm{wt} \%$ C60.

\section{EDS analysis}

To make sure whether the black needles were made up of $\mathrm{C} 60$, the chemical composition of the $\mathrm{C} 60$ needle were further analyzed via EDS. The analysis results of C60 needles in PLLA composites with 1wt\% C60 indicated the black needle contained $88.1 \mathrm{wt} \%$ (95.62atom percent) carbon element and $11.9 \mathrm{wt} \%$ (4.58atom percent) chlorine element, which implied the needle was mainly assembled by $\mathrm{C} 60$ molecules. The chlorine element might come from the residual solvent absorbed or trapped by $\mathrm{C} 60$ molecules during evaporating.

\section{DSC analysis}

C60, as an heterogeneous nucleating agent for PLLA matrix, could induce the PLLA molecules to crystallize during solvent evaporation, in turn, the crystallization of PLLA might also influence the assembling of C60 and the formation of C60 needles. DSC characterization was carried out to study the nucleation action of $\mathrm{C} 60$ on PLLA molecules. The melting enthalpy change during the second heating process was recorded to study the effect of C60 on the crystallinity of PLLA matrix. As is shown in Fig. 3 and Table 1, no cold crystallization happened during the second heating process of neat PLLA, the melting peak top temperature of PLLA crystallites formed and the relative crystallinity $\left(\mathrm{X}_{\mathrm{c}}\right)$ of PLLA was $151.2^{\circ} \mathrm{C}$ and $0.75 \%$, respectively. In the case of PLLA containing $1.0 \mathrm{wt} \% \mathrm{C} 60$, there is an obvious cold crystallization process that starts at $127.4^{\circ} \mathrm{C}$, which indicates the nucleation action of C60. Due to the nucleation effect of C60, the PLLA in composites crystallized faster thus, the melting peak top temperature of PLLA crystallites in composites was about $0.3^{\circ} \mathrm{C}$ higher than that of neat PLLA, indicating there was a slight increase in the thickness of PLLA crystallites. What is more, the
$\mathrm{X}_{\mathrm{c}}$ of PLLA in composites increased sharply to $7.06 \%$, about nine folds higher than that of neat PLLA.

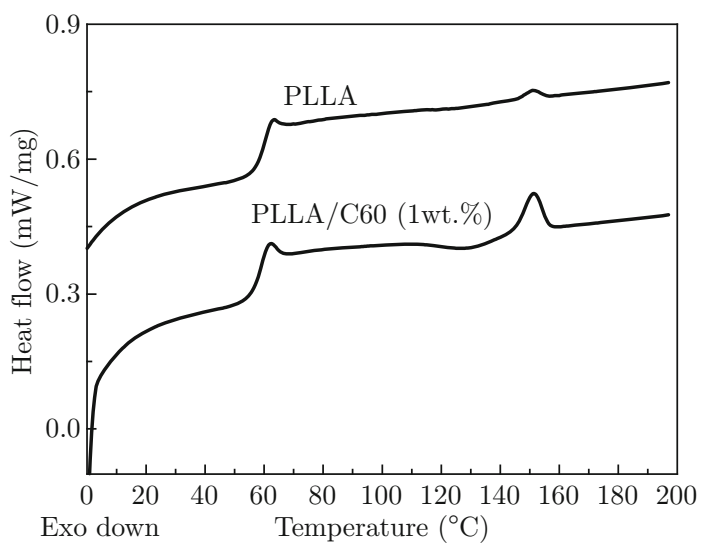

Fig. 3 The DSC $2^{\text {nd }}$ heating curves of (a) neat PLLA and (b) PLLA with $1 \mathrm{wt} \%$ of $\mathrm{C} 60$, respectively.

Table 1 DSC results of the second heating process for neat PLLA and PLLA/C60(1wt\%) composites

\begin{tabular}{lccccc}
\hline Samples & $\mathrm{T}_{\mathrm{c}}\left({ }^{\circ} \mathrm{C}\right)[\mathrm{a}]$ & $\mathrm{T}_{\mathrm{m}}\left({ }^{\circ} \mathrm{C}\right)[\mathrm{b}]$ & $\begin{array}{c}\Delta \mathrm{H}_{\mathrm{c}} \\
(\mathrm{J} / \mathrm{g})[\mathrm{c}]\end{array}$ & $\begin{array}{c}\Delta \mathrm{H}_{\mathrm{m}} \\
(\mathrm{J} / \mathrm{g})[\mathrm{d}]\end{array}$ & $X_{\mathrm{c}}(\%)[\mathrm{e}]$ \\
\hline PLLA & - & 151.2 & - & 0.70 & 0.75 \\
PLLA $/$ & 127.4 & 151.5 & -5.61 & 6.61 & 7.06 \\
C60(1wt\%) & & & & & \\
\hline
\end{tabular}

[a] Crystallization temperature of PLLA. [b] Melting temperature of PLLA. [c] Cold crystallization enthalpy change of PLLA. [d] Melting enthalpy change of PLLA. [e] Relative crystallinity of PLLA.

\section{Assembling mechanism of C60 in PLLA matrix}

Possible assembling mechanism of C60 needles in PLLA matrix was proposed as follows. With the evaporation of $\mathrm{H}_{2} \mathrm{CCl}_{2}$, the $\mathrm{C} 60$ solution became supersaturated, precipitated $\mathrm{C} 60$ would crystallize and combine with each other via Van der Waals force. Meanwhile, the molecules of PLLA would condense and crystallize slowly, some C60 could act an effective nucleating agent during solvent evaporation while $\mathrm{H}_{2} \mathrm{CCl}_{2}$ [12] was used as the common solvent for both C60 and PLLA. As indicated by the aforesaid DSC analysis, PLLA could easily crystallize under the nucleating action of C60. The ordered alignment of PLLA molecular chain during crystallization could, in turn, promote the rest of C60 to migrate into the amorphous area or crystal boundary area of PLLA matrix. It is very likely that the C60 needle be assembled by the enriched C60 along PLLA crystal boundaries via Van der Waals force.

\section{Conclusion}

Needle-like C60 assembling has been obtained in preparing PLLA/C60 composites. The morphology of 
the C60 needle studied by optical microscope and scanning electron microscope (SEM) show that the amount of $\mathrm{C} 60$ in the mixing system have some influences on the length of C60 needles. The largest C60 needles could have a diameter of $50 \mu \mathrm{m}$ and a length of $1.6 \mathrm{~mm}$. The energy dispersive spectra (EDS) analysis indicated the C60 needle was mainly composed of C60, DSC analysis indicated C60 accelerated the crystallization and lift the relative crystallinity of PLLA matrix. The results indicate the addition of PLLA influence the assembling behavior of $\mathrm{C} 60$. On the one hand, with the evaporation of $\mathrm{H}_{2} \mathrm{CCl}_{2}, \mathrm{C} 60$ precipitated from solution would crystallize and combine with each other via Van der Waals force. On the other hand, PLLA crystallize easily under the nucleating action of C60, the orderly movement of PLLA molecules would drive C60 to migrate into amorphous area and crystal boundary area, the C60 located in the crystal boundary area of PLLA matrix might tend to assemble into C60 needles via Van der Waals force. The assembly of C60 in other semicrystalline polymer matrix will be investigated in our future work.

\section{Acknowledgments}

We owe great thanks for the C60 supplied by NIMS and the support from Prof. Guangzhe Piao in Key Lab of Rubber-plastics of Ministry of Education/Shandong Provincial Key Laboratory of Rubber-plastics, Qingdao University of Science \& Technology (QUST), Qingdao 266042, China.

\section{References}

[1] T. Nakanishi, W. Schmitt, T. Michinobu, D. G. Kurthac and K. Ariga, Chem. Commun. 15, 5982
(2005). http://dx.doi.org/10.1039/b512320h

[2] H. Ji, J. Hu, L. Wan, Q. Tang and W. Hu, J. Mater. Chem. 18, 328 (2008). http://dx.doi.org/10.1039/ b712696d

[3] J. Geng, W. Zhou, P. Skelton, W. Yue, I. A. Kinloch, A. H. Windle and B. F. G. Johnson, J. Am. Chem. Soc. 130, 2527 (2008). http://dx.doi.org/10.1021/ ja076392s

[4] T. Tsuchiya, R. Kumashiro, K. Tanigaki, Y. Matsunaga, M. O, Ishitsuka, T. Wakahara, Y. Maeda, Y. Takano, M. Aoyagi,T. Akasaka, M. T. H. Liu, T. Kato, K. Suenaga, J. S. Jeong, S. Iijima, F. Kimura, T. Kimura and S. Nagaser, J. Am. Chem. Soc. 130, 450 (2008). http://dx.doi.org/10.1021/ja710396n

[5] C. H. Tan, P. Ravi, S. Dai, K. C. Tam and L. H. Gan, Langmuir 20, 9882 (2004). http://dx.doi.org/ 10.1021/la049747j

[6] X. Wang, S. H. Goh, Z. H. Lu, S. Y. Lee and C. Wu, Macromolecules 32, 2786 (1999). http://dx.doi.org/ 10. 1021/ma981771e

[7] J. Yang, L. Li and C. Wang, Macromolecules 36, 6060 (2003). http://dx.doi.org/10.1021/ma025909b

[8] P. Ravi, S. Dai, C. Wang and K. C. Tam, J. Nanosci. Nanotech. 7, 1176 (2007). http://dx.doi.org/10. 1166/jnn. 2007.456

[9] Bruno Schmaltz, Martin Brinkmann and Claude Mathis, Macromolecules 37, 9056 (2004). http://dx. doi.org/10.1021/ma048421e

[10] W. Liu, R. Liu, W. Wang, W. Li, W. Liu, K. Zheng, L. Ma,Y. Tian, Z. Bo and Y. Huang, J. Phys. Chem. C 113, 11385 (2009). http://dx.doi.org/10.1021/ jp900042h

[11] H. Tsuji, H. Takai, N. Fukuda and H. Takikawa, Macromol. Mater. Eng. 291, 325 (2006). http://dx. doi.org/10.1002/mame. 200500371

[12] H. Tsuji, Y. Kawashima and H. Takikawa, J. Polymer Sci. Part B: Polymer Phys. 45, 2167 (2007). http:// dx.doi.org/10.1002/polb. 21215 